\title{
Congestion effect on renewable energy production efficiency in Europe
}

\author{
Corrado lo Storto* \\ University of Naples Federico II, Department of Industrial Engineering, Piazzale V. Tecchio 80, \\ 80125 Naples, Italy
}

\begin{abstract}
In the last decade the renewable energy facilities have become very important for generating electricity in Europe. Estimating the production efficiency of renewable energy industry is thus a major concern of governments. This paper implements Data Envelopment Analysis (DEA) to measure efficiency in the generation of electricity from renewable sources during 2002-2011 in 31 European countries. As input congestion may introduce bias in the efficiency analysis, an improved DEA model is used to correct and avoid efficiency underestimation.
\end{abstract}

\section{Introduction}

In Europe, the industry of the electricity generation has experienced profound changes since the beginning of the 2000s. The slowdown of energy demand, the need for climate change mitigation, the search for greater efficiency, security and affordability of energy provision, and the decrease of costs thanks to technological innovation have put pressure on the industry to change the mix of energy sources. In this new landscape, renewable energy sources have largely contributed to this change. Indeed, renewable energy sources have a higher mitigation potential of greenhouse gas emissions and lower health and environment impact than fossil fuel sources [1]. Furthermore, as they allow reducing fossil fuel imports and stimulating the creation of jobs, skills and technological innovation, renewable energy sources contribute to economic and social growth, too. In Europe, contribution to fossil fuel import savings was about $€ 16$ billion in 2015 , while forecasts predict that savings will be $€ 58$ billion in 2030 [2]. According to statistics released by EUROSTAT, between 2004 and 2014 the relative weight of renewable energy sources in the generation of electricity in the EU-28 countries grew from $13.5 \%$ to $24.9 \%$ [3]. In 2014, the EU-28 countries had the largest solar-PV and wind power capacity in the world.

Contrarily to investment to increase electricity generation through conventional sources, investment leveraging on the utilization of renewable energy sources requires considerable amount of money per energy generated to build plants, but low operating expenditures. Thus, investment decisions to add new electric power capacity from renewable sources should take into account a number of factors, such as investment risk, cost of capital, future demand, technological innovation trends. National governments have an important role to promote investment by designing policy and industry regulation mechanisms. In particular,

\footnotetext{
*Corresponding author: corrado.lostorto@unina.it
} 
policymakers need to address the choice of the renewable sources to invest on in order to meet longer terms objectives and achieve the higher efficiency in the generation of electricity. Thus, an important issue in the energy policy is to understand what renewable sources contribute more efficiently to the aggregate production of electricity in a country.

This paper adopts Data Envelopment Analysis (DEA) to measure efficiency in the generation of electricity from major renewable sources from 2002 to 2011 in 31 European countries. As input congestion may introduce bias in the efficiency analysis, an improved DEA model is used to measure it to correct and avoid efficiency underestimation.

The rest of the paper unfolds as follows. Section 2 illustrates the method implemented to calculate efficiency and evaluate the influence of congestion. Section 3 provides information relative to dataset and variables used. Section 4 and section 5 respectively present major results and conclusion.

\section{Method}

DEA is a well known non-parametric technique utilized to conduct benchmarking analyses and investigate how to improve performance, specifically efficiency. DEA has been applied in a wide range of industries and contexts, i.e. drinking water management, banking, transportation, healthcare, manufacturing, automotive, energy, education, high-performance computing urban management, etc. [4-14]. In the DEA approach a benchmarking frontier is generated as a set of linear combinations of inputs and outputs of a number of units to be evaluated denominated DMUs. The relative efficiency of DMUs is calculated by running the same number of linear programming models, one for each DMU [15]. A DMU $k$ lying on the envelopment frontier is $100 \%$ efficient, and it is unable to increase one of the outputs without increasing at least one input or decreasing at least one of the other outputs. Vice versa, if DMU $k$ is placed under the frontier it is considered inefficient.

In this study, each country $\mathrm{C}_{k}$ is a DMU $k$ in the dataset that is associated to a production function which converts $X=\left(x_{i j}\right) \in \mathfrak{R}^{m \times n}$ inputs (i.e., maximum power generation capability of power plants using a certain renewable source in the country) into $\boldsymbol{Y}=\left(x_{i j}\right) \in \mathfrak{R} \mathfrak{R}^{s \times n}$ outputs (i.e., electricity generated by all power plants in the country using the same renewable source). Technical efficiency (TE) of DMU $k$ denotes its ability to produce the maximum amount of outputs by consuming the same amount of inputs or to produce a given amount of outputs with the minimum consumption of inputs, independently of any input and output price set.

Assuming costant returns to scale (CRS), the linear programing model to compute technical efficiency in an input-orientation is as follows

$$
\begin{array}{ll}
T E^{C R S}= & D F^{i}\left(x_{k}, y_{k}\right)=\min _{\theta, z} \\
\text { s.t. } & Y^{\prime} z \geq y_{k} \\
& X^{\prime} z \leq \theta x_{k} \\
& \theta \geq 0, z \geq 0
\end{array}
$$

where $\theta=D F_{i}\left(x_{k}, y_{k}\right)$ is the radial input efficiency measure of DMU $k$, and $z$ is an intensity variable.

The CRS assumption can be easily changed to variable returns to scale (VRS) by adding the constraint $\boldsymbol{I} z=1$, where $\boldsymbol{I}$ is a $n \times 1$ unity vector.

Usually increases in inputs cause increases in outputs. Conventional DEA provides a measure of efficiency that is based on the assumption of strong (or freely) disposability (SD) of inputs. Inputs are strongly disposable if an input increase does not decrease outputs. Under this assumption, all energy power capacity inputs are radially decreased when an inefficient country is projected onto the efficient envelopment frontier. 
However, there are situations where increasing one or more inputs may reduce one or more outputs. In such situations there is congestion in inputs or production process and increasing one or some inputs to produce more outputs is undesirable [16]. Weak disposability (WD) is the term used to refer to such situation.

In order to investigate if there is congestion in the production process, Färe and Grosskopf [17] suggest to assume both strong and weak input disposability at the same time. Technical efficiency TE can be decomposed into the product of three components as follows

$$
T E^{C R S}=T E^{V R S} \times S E \times C N
$$

where

$T E^{C R S}=D F_{i}\left(x_{k}, y_{k} \mid \mathrm{CRS}, \mathrm{SD}\right)$ measures the total efficiency of DMU $k$ under the assumption of strong input disposability

$T E^{V R S}=D F_{i}\left(x_{k}, y_{k} \mid \mathrm{VRS}, \mathrm{WD}\right)$ measures pure technical efficiency of DMU $k$ under the assumptions of VRS and weak input disposability

$S E=D F_{i}\left(x_{k}, y_{k} \mid \mathrm{CRS}, \mathrm{SD}\right) / D F_{i}\left(x_{k}, y_{k} \mid \mathrm{VRS}, \mathrm{SD}\right)$ measures scale efficiency of DMU $k$ that is related to the size. If $S E<1$ there are scale inefficiencies.

$C N=D F_{i}\left(x_{k}, y_{k} \mid \mathrm{VRS}, \mathrm{SD}\right) / D F_{i}\left(x_{k}, y_{k} \mid \mathrm{VRS}, \mathrm{WD}\right)$ measures congestion of DMU $k$ as a consequence of lack of strong disposability of its inputs. If $\mathrm{CN}<1$ congestion occurs.

\section{Data, variables and model specification}

The dataset includes 31 European countries. Data relative to both the installed power capacity and electricity generation from renewable sources between 2002 and 2011 were retrieved from the European Commission statistical database. The production function model specification includes 4 inputs and 1 output. Particularly, the following inputs were used: the total installed capacity of the country relative to energy generation from hydro, wind, solar-PV and waste sources. Other forms of renewable sources have been excluded because of their scarce diffusion across sample countries. The total yearly electricity generated from the renewable sources considered in the study was used as the unique output. Measurement units are in Mw.

All inputs and output have been divided by their respective means to reduce computational scaling problems.

\section{Results}

Table 1 presents individual measurements relative to technical efficiency (TE) from 2002 to 2011. Scores were calculated under the assumptions of constant returns to scale and input strong disposability. Figures show an extremely varied picture. Countries largely differ with respect to their achieved efficiency. For instance, technical efficiency of total installed capacity in Italy is between 0.300 and 0.469 , while in Ireland it is between 0.173 and 1.000 . The behavior of technical efficiency over years was generally very unsteady. However, for some countries more evident patterns can be identified. Efficiency scores remained rather unchanged for Italy, except in 2009 and 2010. Vice versa, technical efficiency increased in Belgium, Spain, Lithuania, UK. Romania is the only country in which technical efficiency achieved the maximum value and remained stable over the observation period. 
Table 1. Technical efficiencies between 2002 and 2011.

\begin{tabular}{|c|c|c|c|c|c|c|c|c|c|c|}
\hline \multirow{2}{*}{ Country } & \multicolumn{10}{|c|}{ TE (CRS, SD) } \\
\hline & 2002 & 2003 & 2004 & 2005 & 2006 & 2007 & 2008 & 2009 & 2010 & 2011 \\
\hline Belgium & 0.223 & 0.204 & 0.235 & 0.261 & 0.310 & 0.351 & 0.385 & 0.394 & 0.418 & 0.540 \\
\hline Bulgaria & 0.322 & 0.378 & 0.329 & 0.417 & 0.421 & 0.456 & 0.465 & 0.418 & 0.334 & 0.374 \\
\hline Czech Republic & 0.341 & 0.190 & 0.266 & 0.241 & 0.257 & 0.212 & 0.214 & 0.259 & 0.322 & 0.507 \\
\hline Denmark & 1.000 & 1.000 & 1.000 & 1.000 & 1.000 & 1.000 & 1.000 & 1.000 & 1.000 & 0.466 \\
\hline Germany & 0.702 & 0.688 & 0.810 & 0.824 & 0.790 & 0.858 & 0.830 & 0.757 & 0.841 & 0.429 \\
\hline Estonia & 0.490 & 0.967 & 0.597 & 1.000 & 1.000 & 1.000 & 1.000 & 1.000 & 1.000 & 0.360 \\
\hline Ireland & 0.514 & 0.432 & 0.501 & 0.655 & 0.819 & 0.908 & 1.000 & 1.000 & 1.000 & 0.173 \\
\hline Greece & 0.221 & 0.674 & 0.333 & 0.572 & 0.708 & 0.267 & 0.321 & 0.801 & 0.547 & 1.000 \\
\hline Spain & 0.328 & 0.502 & 0.447 & 0.400 & 0.453 & 0.493 & 0.496 & 0.557 & 0.773 & 1.000 \\
\hline France & 0.440 & 0.424 & 0.426 & 0.378 & 0.402 & 0.425 & 0.456 & 0.427 & 0.468 & 0.461 \\
\hline Croatia & 0.632 & 0.602 & 0.800 & 0.691 & 0.665 & 0.617 & 0.734 & 0.781 & 1.000 & 0.358 \\
\hline Italy & 0.393 & 0.364 & 0.404 & 0.355 & 0.353 & 0.323 & 0.387 & 0.440 & 0.469 & 0.300 \\
\hline Latvia & 0.320 & 0.291 & 0.376 & 0.419 & 0.324 & 0.345 & 0.392 & 0.431 & 0.750 & 0.515 \\
\hline Lithuania & 0.150 & 0.185 & 0.177 & 0.155 & 0.147 & 0.194 & 0.202 & 0.231 & 0.398 & 0.511 \\
\hline Luxembourg & 0.150 & 0.137 & 0.132 & 0.140 & 0.142 & 0.145 & 0.149 & 0.131 & 0.216 & 0.491 \\
\hline Hungary & 0.672 & 0.832 & 1.000 & 1.000 & 1.000 & 1.000 & 1.000 & 1.000 & 1.000 & 0.288 \\
\hline The Netherlands & 1.000 & 1.000 & 1.000 & 1.000 & 1.000 & 0.927 & 1.000 & 1.000 & 1.000 & 0.708 \\
\hline Austria & 0.609 & 0.504 & 0.542 & 0.538 & 0.523 & 0.511 & 0.494 & 0.522 & 0.506 & 0.680 \\
\hline Poland & 0.448 & 0.347 & 0.350 & 0.382 & 0.300 & 0.348 & 0.366 & 0.408 & 0.535 & 0.608 \\
\hline Portugal & 0.318 & 0.588 & 0.360 & 0.221 & 0.426 & 0.417 & 0.369 & 0.472 & 0.722 & 1.000 \\
\hline Romania & 1.000 & 1.000 & 1.000 & 1.000 & 1.000 & 1.000 & 1.000 & 1.000 & 1.000 & 1.000 \\
\hline Slovenia & 0.578 & 0.495 & 0.685 & 0.586 & 0.568 & 0.519 & 0.633 & 0.705 & 0.599 & 0.622 \\
\hline Slovakia & 0.584 & 0.352 & 0.359 & 0.441 & 0.409 & 0.475 & 0.426 & 0.512 & 0.359 & 0.400 \\
\hline Finland & 0.642 & 0.600 & 0.716 & 0.597 & 0.604 & 0.713 & 0.886 & 0.651 & 0.695 & 0.412 \\
\hline Sweden & 0.678 & 0.544 & 0.575 & 0.669 & 0.554 & 0.588 & 0.624 & 0.568 & 0.651 & 0.759 \\
\hline United Kingdom & 0.388 & 0.350 & 0.423 & 0.498 & 0.543 & 0.549 & 0.588 & 0.635 & 0.616 & 1.000 \\
\hline Iceland & 1.000 & 1.000 & 1.000 & 1.000 & 1.000 & 1.000 & 1.000 & 1.000 & 1.000 & 0.761 \\
\hline Norway & 0.770 & 0.619 & 0.637 & 0.793 & 0.668 & 0.755 & 0.762 & 0.684 & 0.794 & 1.000 \\
\hline Switzerland & 0.461 & 0.453 & 0.432 & 0.407 & 0.392 & 0.441 & 0.450 & 0.443 & 0.440 & 1.000 \\
\hline F Y R of Macedonia & 0.283 & 0.504 & 0.444 & 0.454 & 0.483 & 0.299 & 0.242 & 0.367 & 1.000 & 0.512 \\
\hline Turkey & 1.000 & 1.000 & 1.000 & 1.000 & 1.000 & 1.000 & 1.000 & 1.000 & 1.000 & 0.580 \\
\hline
\end{tabular}

Figure 1 displays the plot of TE(CRS,SD), TE(VRS, WD), SE and CN means from 2002 to 2011. The graph clearly shows that on average technical efficiency calculated assuming strong input disposability continuously increased till 2009, but after 2010 it drastically diminished, probably as a consequence of the downward trend of the European 
economy. However, the trend of the SE curve suggests that the improvement of the scale size operations had a not negligible weight in the increasing of efficiency scores. Indeed, the steady increase of the SE measurements indicates that values of both TE(CRS,SD) and TE(VRS,SD), on average, get closer and closer together over the years (as SE is closer to 1). Finally, the curve trend related to $\mathrm{CN}$ emphasizes that the effect of input congestion compensate for the efficiency improvement determined by scale economies, particularly from 2006 to 2009.

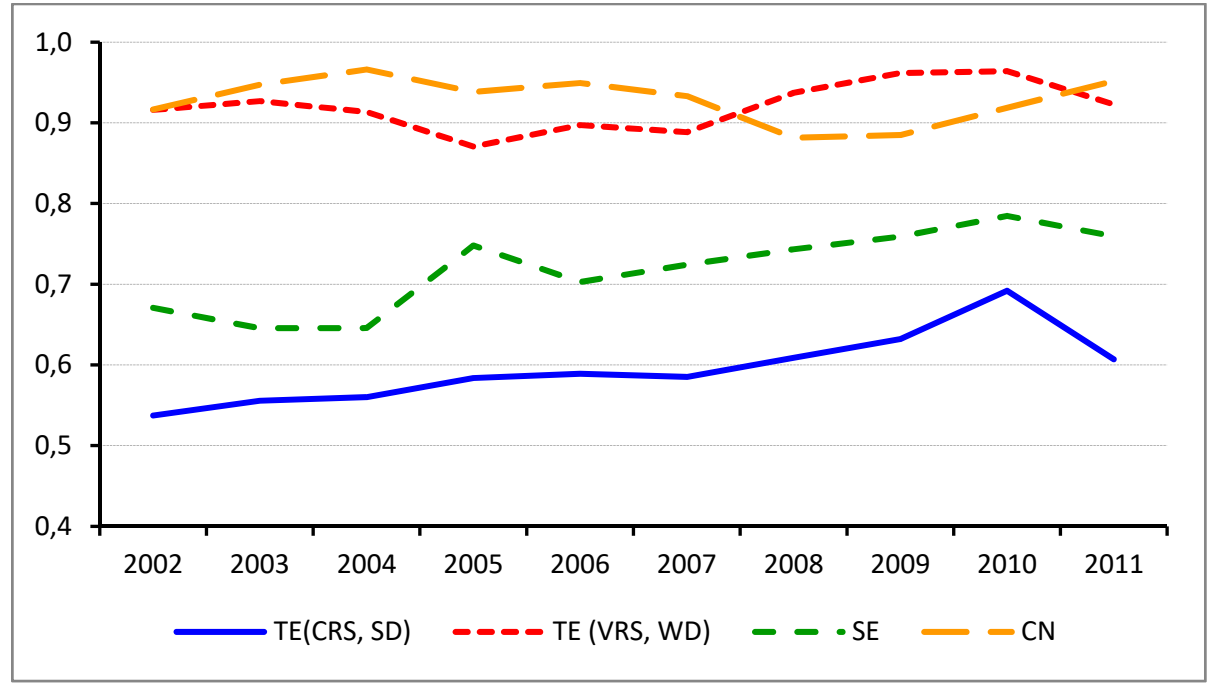

Fig. 1. Means plot of TE(CRS,SD), TE(VRS), SE and CN from 2002 to 2011.

\section{Conclusion}

This paper has illustrated the results of benchmarking study which has measured the production efficiency relative to the generation of electricity from renewable sources in 31 European countries between 2002 and 2011. The study has implemented Data Envelopment Analysis to compute efficiency. Additionally, the effect on efficiency of both input congestion and scale economies have been evaluated.

Results indicate that countries largely differ with respect to their achieved efficiency. The behavior of technical efficiency measurements over years was generally very unsteady. Finally, to a large extent efficiency of installed renewable power capacity was influenced by both scale economies and input congestion.

These findings suggest that in designing market regulation and incentives mechanisms, policy-makers should take into account not only efficiency, but also congestion and scale economies issues in order to identify the optimal mix of renewable sources.

This study considered only the country energy generation capacities from renewable sources as inputs and the amount of electricity generated from these latter as output of the electricity production model. Consequently, it has not provided a comprehensive picture of the generation of electricity in the countries of the sample. Future research might include further variables in the efficiency model, such as the electricity generation capacity from fossil fuels, the total generation of electricity in the country, the amount of $\mathrm{CO}_{2}$ emissions. Additionally, a two step DEA analysis might be purposefully performed to correct efficiency and congestion measurements by taking into account the influence of external variables, i.e. national GDP, country size and economic structure, etc. [18]. 


\section{References}

1. http://fs-unep-centre.org/sites/default/files/publications/ globaltrendsinrenewableenergyinvestment2016lowres_0.pdf

2. EEA, Renewable energy in Europe 2016 - Recent growth and knock-on effect, (European Environment Agency Report no. 4/2016, 2016, Copenhagen)

3. http://epp.eurostat.ec.europa.eu/statisticsexplained

4. T. Agasisti, Education Economics 19, 199-224 (2011)

5. J.R. Barth, C. Lin, Y. Ma, J. Seade, F.M. Song, J Bank Financ 37, 2879-2892 (2013)

6. A.G. Goncharuk, C. lo Storto, Energ Policy 101, 456-466 (2017)

7. B. Hollingsworth, Health Econ 17, 1107-1128 (2008)

8. C. lo Storto, B. Capano, Ener Educ Sci Tech - A 32, 3061-3072 (2014)

9. C. lo Storto, B. Capano, ARPN J Eng Appl Sci 11, 6234-6239 (2016)

10. C. lo Storto, Water 5, 2058-2079 (2013)

11. C. lo Storto, Appl Mech Mater 309, 335-341(2013)

12. C. lo Storto, Inz Ekon 25, 320-332 (2014)

13. C. lo Storto, Cities 51, 52-63 (2016)

14. R.C. Marques, C.P. Barros, Appl Econ Lett 18, 29-37 (2011)

15. A. Charnes, W.W. Cooper, E. Rhodes, Eur J Oper Res 2, 429-444 (1978)

16. R. Fare, L. Svensson, Econometrica 48, 1743- 1753 (1980)

17. R. Fare, S. Grosskopf, Zeitschhrift für Nationalökonomie 43, 257-271 (1983)

18. L. Simar, P.W. Wilson, J. Econ 136, 31-64 (2007) 